International Scientific Journal Theoretical \& Applied Science

p-ISSN: 2308-4944 (print) e-ISSN: 2409-0085 (online)

Year: $2015 \quad$ Issue: $11 \quad$ Volume: 31

Published: $30.11 .2015 \quad \underline{\text { http://T-Science.org }}$
SOI: $1.1 /$ TAS $\quad$ DOI: $10.15863 /$ TAS

Gulbarshin Spanovna Konkina

Ph.D, The Department of History of Kazakhstan and law, bases of economy

Arkalyk State Pedagogical Institute named after I.Altynsarin, Kazakhstan g.s.konkina@mail.ru

Bibigul Aralbaevna Dosova Academician Y.A.Buketov Karaganda State University, Kazakhstan

SECTION 30. Philosophy.
Amrina Minar

Academician Y.A.Buketov Karaganda State University, Kazakhstan

Nazira Izbastyyevna Yessimkhanova Master of pedagogical sciences Senior lecturer of the Department of History of

Kazakhstan and law, bases of economy Arkalyk State Pedagogical Institute named after I.Altynsarin, Kazakhstan

\title{
METHODOLOGICAL BASE OF THE HISTORICAL SCIENCE USSR: PROBLEM OF EFFECTIVENESS IN MODERN STAGE
}

\footnotetext{
Abstract: This article analyzes the methodological basis of Soviet historical science.

Key words: historiography, methodology, formation approach, methodological pluralism, the principle of subsidiarity.

Language: Russian

Citation: Konkina GS, Dosova BA, Minar A, Yessimkhanova NI (2015) METHODOLOGICAL BASE OF THE HISTORICAL SCIENCE USSR: PROBLEM OF EFFECTIVENESS IN MODERN STAGE. ISJ Theoretical \& Applied Science 11 (31): 18-22.

Soi: http://s-o-i.org/1.1/TAS-11-31-4 Doi: crossef http://dx.doi.org/10.15863/TAS.2015.11.31.4

\section{МЕТОДОЛОГИЧЕСКАЯ ОСНОВА ИСТОРИЧЕСКОЙ НАУКИ СССР: ПРОБЛЕМА ЭФФЕКТИВНОСТИ В СОВРЕМЕННЫХ УСЛОВИЯХ}

Аннотация: Статья посвящена анализу методологической основы советской исторической науки.

Ключевые слова: историческая наука, методология, формационный подход, циивлизационный подход, методологический плюрализм, принциип дополнительности.
}

Каждая из наук, в тот или иной исторический отрезок времени, неизбежно сталкивается с проблемой обновления или пересмотра своего методологического инструментария. Историческая наука является не исключением. Более того, она подвержена таким процессам больше других наук в силу непосредственного отношения к судьбе человеческого общества. А общество людей, как живой организм, всегда требует постоянного мониторинга способов своего изучения. Тем более что историческая наука всегда была подвержена идеологическому влиянию. Например, советская историческая наука, методологической основой которой был формационный подход. В постсоветский период мы столкнулись с острой полемикой в отношении эффективности теории формаций в исторических исследованиях. Кто же прав в этом основополагающем вопросе постсоветской исторической науки, мы попытались разобраться в данном исследовании.

Необходимость в методологическом обеспечении возникает тогда, когда есть проблема, требующая решения. Старые методы при этом оказываются непригодными. Решение проблемы в этом случае требует знания широты связи объекта, выхода в культуру. В этом случае прослеживается связь науки и культуры, с помощью которой наука в процессе своего развития, особенно в кризисных ситуациях, 
черпает из культуры нормативы, обеспечивающие ее прогресс.

Важной особенностью методологической деятельности является то, что для ее осуществления исследователь расширяет поле своего зрения, как бы выходя за пределы своей науки, тех средств и представлений, того образа мышления и действия, которые являются для нее характерными. Является закономерным то, что в науке после периода, когда сложившийся стиль мышления не подвергается радикальным изменениям, наступает период глобальных научных революций, связанных с преобразованием стиля мышления, при этом отмеченные характеристики знаний подвергаются пересмотру.

В советский период методология исторической науки отражала тот культурный пласт действительности, в основе которой лежала коммунистическая идеология. Отцамиоснователями данной теоретической выкладки, как известно, являются К. Маркс и Ф. Энгельс. В связи с этим, советские историки проявляли огромный интерес к их работам. Ни один труд, посвященный изучению истории человечества, не обходился без цитаты из произведений марксистов. В постперестроечный период интерес к марксистской теории не ослабел, так как большинство исследователей стали ее изучать для более конструктивной критики.

Основные работы К. Маркса и Ф. Энгельса раскрывали суть теории общественноэкономических формаций, а многочисленные комментарии и критика марксистской теории дали нам возможность определить положительные и отрицательные стороны данного подхода в историческом познании [1]. Работы, написанные в советский период, характеризуют исторический материализм как оптимальный и эффективный подход в научном познании общества. Оценки изменяются по мере изменения политической ситуации в стране: все больше появляется отрицательной критики в адрес формационного подхода. В 1990-е годы сложилось неоднозначное отношение к наследию основоположников марксизма: с одной стороны призыв сохранить верность теории, с другой стороны - полный отказ от материалистического понимании истории, с третьей стороны - советы вернуться к «чистому» марксизму, отказавшись от так называемого «советского» периода, четвертые, мнение которых, на наш взгляд, является более реальным - это призыв к качественной и обоснованной критике формационной теории. Не для того, чтобы вынести ей «смертельный приговор», а для того, чтобы реабилитировать ее эвристические возможности в современных условиях. Думаем, что последняя сторона критики более выгодна для постперестроечной исторической науки, так как она позволит более безболезненно перейти на современный этап научного исторического познания, который характеризуется плюрализмом мнений и подходов, а также принципом дополнительности, означающий своего рода «командный» подход в достижении истины.

Вопрос отказа или реабилитации методологии исторической науки советского периода является не праздным для современной казахстанской науки и для всего общества в целом. В частности, о важности исторической науки в становлении суверенного Казахстана пишет в своих работах Н.А. Назарбаев. В трудах Президента Республики Казахстан «На пороге XXI века», «В потоке истории», «Критическое десятилетие» и других поднимаются вопросы возрождения национального самосознания через изучение подлинной истории казахского народа, так как, изучив прошлое народа можно построить надежный «мост» в будущее [2].

Советские, а затем и российские исследователи опубликовали множество работ, посвященных анализу сложившейся ситуации в исторической науке постперестроечного периода. Прежде всего, это работы, в которых описывается методологический кризис в современной исторической науке. Среди авторов можно отметить таких как А.Я. Гуревич, С.С. Неретина, Д.Е. Фурман, Б.Г. Юдин, Г.Г. Дилигенский, В. Алтухов, С. Королев, А. Никифоров, Л. Алаев и других [3]. Данные ученые, высказав идеи по поводу перспектив формационного подхода в исторической науке, призывают полностью не отказываться от методологической основы науки советского периода, так как марксизм, извращенный в советский период, должен быть реабилитирован.

Доперестроечная полемика вокруг общественно-экономических формаций, на наш взгляд, стремилась примирить концепцию с исторической реальностью. Может поэтому вообще не рассматривался вариант отказа от этой «пятичленки». Более того, были предложены даже трех, четырех, шестичленные интерпретации мирового исторического процесса. Поэтому ни о каком продвижении методологической мысли говорить не приходится, так как не было покушения на основы известной всем схемы. После распада Советского Союза исторический материализм переживает трудные времена. На его основные постулаты (последовательная смена общественно-экономических формаций, первичность базиса и вторичность надстройки, неизбежность классовой борьбы и т.д.) обрушилась волна критики. О необходимости существенного пересмотра «закостенелых» догм истмата писали многие исследователи [4]. Но, 
несмотря на дискуссии (например, об азиатском способе производства), формационная «пятичленка» и сейчас становится единственным объяснением всемирно-исторического процесса.

Другой, на наш взгляд, эффективный этап споров ученых-теоретиков наступает после перестроечных событий (середина 1980-1990-х гг.). Этап характеризуется поиском выхода из методологического тупика, так как «все яснее осознается необходимость отказа от догм и стереотипов, сложившихся в советский период» и поэтому «на данном этапе развития науки формационная теория перестала играть роль бесспорной парадигмы изучения мировой истории» $[5$, с.123]. Как альтернатива выдвигается цивилизационная теория. Хотя отказываться полностью от формационного подхода, как считают многие участники дискуссий, происходящие в исторической науке СНГ во второй половине 1980-х-первой половине 1990-х годов, тоже не выход из той ситуации, в которой оказалась историческая наука. При этом отмечаются положительные стороны формационного анализа. Например, «если речь идет о формационном анализе, то та или иная общность (человечество, этнос) изучаются в стадиальном «разрезе», на определенном этапе развития общества. Такой исследовательский подход, по общему мнению ученых, предполагает анализ законов развития, познание этого общества в его внутренней расчлененности, изучение переходов от формации к формации на всех трех уровнях социальной действительности - глобальном, региональном, личностном» [5, с.125]. К тому же широко распространились разнообразные проекты, основанные на идее взаимодополнения теории формаций и теории цивилизаций. Предложения отойти от формационного подхода, заменить его (или дополнить) цивилизационным подходом прозвучали в дискуссиях философов, историков, политологов и т.д. [6].

Российский ученый Л. Алаев считает, что если формационной теории суждено сохраниться, она должна приобрести несколько уровней: «а) глобальный общеисторический абстрактный, на котором фигурируют 3-5 основных этапов, пережитых человечеством, а также теоретические абстрактные модели обществ, в конкретной истории не возможных, но отражающих в «чистой» форме структуры, характерные для каждого из этапов; б) региональный или цивилизационный, на котором на каждом из этапов определяются лидеры и ведомые и, соответственно, регионы первичных и вторичных (третичных) отношений данного этапа, с выделением цивилизационных моделей формаций (типа - «исламский феодализм»); в) локальный («страновой», этнический), на котором общие законы и модели конкретизируются и модифицируются в индивидуальный, уникальный «путь развития»; здесь огромную роль играют экологические условия, политические судьбы, этнические особенности и т.П. Без такой разработки схема формаций останется никому не нужной и отомрет вместе с содержащимся в ней рациональным зерном» [7, с.65].

Не все согласны с мнением о том, что марксизм сохранит свои позиции в XXI веке. «Слишком многое в марксистской философии принадлежит XIX веку», - считает А. Никифоров [8, с.116]. В.В. Ильин тоже считает, что «теоретическая мысль в марксизме атрофировалась, исподволь, медленно, но верно вырождаясь в «защиту», «борьбу с происками», охранение отжившего, а идеология, приобретая статус государственной, становилась инструментом преобразования действительности, манипулятором человеческих судеб и жизней» [4, c.63].

Надо отметить, что в 1991-1992 гг. журнал «Общественные науки» развернул на своих страницах спор на тему: «Переживет ли марксизм перестройку?». В дискуссии приняли участие многие ученые [6]. Например, Н. Козлова убеждена в том, что советский вариант марксизма - воплощение «научной идеологии». Это теория претендовала на роль науки наук, которой все ясно и которая одна владеет истиной в последней инстанции. Людей, которые пришли в науку после революции «интересует не столько знание - истина, сколько знание - сила. В их рассуждениях делался акцент на использование теории не с целью познания реальности, а с целью ее изменения посредством приложения к реальности готовой теории, не затемняя «сути» дискуссиями, которые могут увести в сторону от заветной цели» [9, с.66-67].

Российский ученый И.Д. Ковальченко, оставаясь убежденным сторонником марксистской философии истории и работая в рамках официальной советской историографии, все же не был догматиком. В последней опубликованной работе «Сущность и особенности общественно-исторического развития (Заметки о необходимости обновленных подходов)», Иван Дмитриевич писал, что «вопервых, следует напрочь исключить какие бы то ни было претензии на возможность создания универсальных и абсолютных теорий и методов исторического познания. Это обусловлено неисчерпаемостью черт и свойств общественноисторического развития, что делает невозможным выработку каких бы то ни было всеохватывающих теорий. Во-вторых, следует учитывать, что любая научная теория, основанная на анализе и обобщении исторической 
действительности, а не на априорных конструкциях и отрывочных фактах, содержит то или иное рациональное зерно и тем самым вносит определенный вклад в развитие общественнонаучной мысли...Учет и использование в исследовательской практике всего того в теории и методологии обществознания, что позволяет расширить и углубить, т.е. более адекватно отразить суть явлений и процессов объективной исторической реальности, и выражает переход от догматического гносеологического монизма (в любых его проявлениях) к познавательному плюрализму. Именно в этом состоит суть научного плюрализма, а не абсолютизации права ученого трактовать ход того же исторического развития по своему субъективному представлению, как нередко утверждалось и утверждается в настоящее время в связи с поисками новых подходов в познании прошлого. В-третьих, любая философско-историческая теория позволяет выработать ту или иную концепцию исторического развития, которая всегда исторична, т.е. в большей или меньшей мере ограничена. Иначе говоря, характеристика сущности тех или иных общественных отношений на основе той или иной теории всегда справедлива лишь в определенных исторических границах...Наконец, в-четвертых, любой социологической теории и конкретной исторической концепции изначально присущи и определенные ошибки и просчеты...Нужен синтез идей и методов, а не механической отбрасывание одних из них (что сейчас наиболее активно происходит по отношению к марксизму) и замена их другими (чаще всего субъективноидеалистическими)» [10, с.25-26].

Главная причина кризиса современной исторической науки, по-нашему мнению, не марксистско-ленинская методология сама по себе, а то состояние науки (напрямую связанное с состоянием общества в целом), которое мы определили бы как методологический монополизм, придавший «застывшей» марксистской теории статус единственной истины. Между тем становится вполне очевидным, что ни одно, даже самое совершенное методологическое построение, в том числе и обновленный марксизм, не может охватить всего многообразия действительности, всех ее сторон и глубинных смыслов, выполнить роль супертеории.

Таким образом, советские историки руководствовались в историческом познании теорией социально-экономических формаций.
Поэтому такого рода монизм создал известные проблемы исторического познания в постсоветский период. Выход из методологического тупика виделся многими в отходе от исторического материализма и приобщение к другим подходам, например, к цивилизационному. В современных условиях развития исторической науки пришло понимание того, что сотрудничество методологических подходов сможет вывести постсоветскую историческую науку из сложившейся кризисной ситуации. Именно методологический плюрализм, являясь характерной чертой современного постнеклассического этапа в истории науки, будет способствовать безболезненному вхождению в современный методологический инструментарий постсоветской исторической науки формационного подхода. Принцип дополнительности, в свою очередь, сыграет огромную роль для равноценного нахождения в едином научном пространстве формационной и других теорий, так как это приведет к объективным исследовательским результатам.

Перспектива исторического познания видится в синтезе формационного, цивилизационного и других подходов современного периода в истории методологии науки. В связи с этим, если современная историческая наука заинтересована в выходе из методологического тупика, то она не должна отбрасывать достижения предыдущих этапов в истории методологии науки в целом и исторической, в частности. Так как от этого зависит сохранение преемственности опытного знания, которое будет способствовать сохранению положительных черт достижений прошлого в исторической науке и станет прочным фундаментом будущего исторической науки. Поэтому необходима отдача приоритета в исторических исследованиях методологическому плюрализму и принципу дополнительности. Это позволит исторической науке методологически обогатиться, то есть, не отказываясь от прежней методологической платформы - теории общественно-экономических формаций, использовать в познании истории другие подходы - цивилизационный подход, обретший популярность в постперестроечное время и другую методологическую перспективу, которая в будущем представит новый контур парадигмы современной научной картины мира. 


\begin{tabular}{l|lrl|l|ll} 
& ISRA (India) & $=\mathbf{1 . 3 4 4}$ & SIS (USA) & $=\mathbf{0 . 9 1 2}$ & ICV (Poland) & $=\mathbf{6 . 6 3 0}$ \\
Impact Factor: & ISI (Dubai, UAE) $=\mathbf{0 . 8 2 9}$ & PUHIL (Russia) $=\mathbf{0 . 1 7 9}$ & PIF (India) & $=\mathbf{1 . 9 4 0}$ \\
& GIF (Australia) & $\mathbf{0 . 5 6 4}$ & ESJI (KZ) & $=\mathbf{1 . 0 4 2}$ & & \\
\hline JIF & $=\mathbf{1 . 5 0 0}$ & SJIF (Morocco) $=\mathbf{2 . 0 3 1}$ & & \\
\hline
\end{tabular}

\section{References:}

1. Rakitov AI (1982) Istoricheskoe poznanie: Sistemno-gnoseologicheskiy podkhod. Moscow: Politizdat, 1982. 303 p.

2. Nazarbaev NA (1999) V potoke istorii. Almaty: Atamyra, 1999. 294 p.

3. Gurevich AY (1990) Sotsial'naya istoriya i istoricheskaya nauka // Voprosy filosofii. 1990. № 4. pp.23-29.

4. Il'in VV (1991) Teoreticheskaya mysl' v marksizme atrofirovalas' // Obshchestvennye nauki i sovremennost'. 1991. № 2. pp.59-66.

5. Baturina LL (1997) V poiskakh vykhoda iz metodologicheskogo tupika. Obzor diskussiy pervoy poloviny 90-kh godov // Vestnik Karagandinskogo universiteta. 1997. № 2. pp.123-128.

6. Voprosy filosofii. 1989. № 10; Doklady na Uchenom Sovete IMEMO v «Mirovaya ekonomika i mezhdunarodnye otnosheniya». 1991. № 5, 6, 9 .
7. Alaev L (1991) Marksizm i problemy obnovleniya teorii // Mirovaya ekonomika i mezhdunarodnye otnosheniya. 1991. № 4 . pp.60-69.

8. Nikiforov A (1990) Perezhivet li marksizm perestroyku? //Obshchestvennye nauki i sovremennost'. 1990. № 3. pp.115-129.

9. Kozlova N (1991) Ideologizatsiya nauki privela k uproshcheniyu kul'tury // Obshchestvennye nauki i sovremennost'. 1991. № 2. pp.66-74.

10. Koval'chenko ID (1995) Sushchnost' i osobennosti obshchestvenno-istoricheskogo razvitiya (Zametki o neobkhodimosti obnovlennykh podkhodov)//Istoricheskie zapiski. Teoreticheskie i metodologicheskie problemy istoricheskikh issledovaniy. Vyp. 1 (119).- Moscow, 1995. 